\title{
Dubai Primary Health Care Centers Conformation to WHO Age-Friendly Primary Healthcare Recommendations
}

\author{
Tamer Mohamed Farid Abdellatif ${ }^{*}$, Amal Mohamad Saleh Abdulrahim Al Jaziri' ${ }^{1}$ \\ Manal Mohammad Omran Taryam², Nahed AbdulKhaleq Monsef ${ }^{3}$, Amel Ibrahim Buharoun", \\ Salah Ahmed Mohamed Elbadawi ${ }^{3}$, Moulham Saleh Ashtar ${ }^{3}$
}

${ }^{1}$ Elderly Care Unit, Health Affairs Department, Primary Health Care Services Sector, Dubai Health Authority, Dubai, United Arab Emirates

${ }^{2}$ Primary Health Care Services Sector, Dubai Health Authority, Dubai, United Arab Emirates

${ }^{3}$ Health Affairs Department, Primary Health Care Services Sector, Dubai Health Authority, Dubai, United Arab Emirates

${ }^{4}$ Health Centres Department, Primary Health Care Services Sector, Dubai Health Authority, Dubai, United Arab Emirates

Email: *Tamer.M.Farid@gmail.com

How to cite this paper: Farid, T.M., Al Jaziri, A.M., Taryam, M.O., Monsef, N.A., Buharoun, A.I., Elbadawi, S.A. and Ashtar, M.S. (2017) Dubai Primary Health Care Centers Conformation to WHO Age-Friendly Primary Healthcare Recommendations. Advances in Aging Research, 6, 83-92. https://doi.org/10.4236/aar.2017.66009

Received: August 25, 2017

Accepted: October 8, 2017

Published: October 11, 2017

Copyright $\odot 2017$ by authors and Scientific Research Publishing Inc. This work is licensed under the Creative Commons Attribution International License (CC BY 4.0).

http://creativecommons.org/licenses/by/4.0/

\begin{abstract}
The WHO project for conforming PHC to requirements of all age groups has resulted in publishing a toolkit for age-friendly PHC in 2008. The toolkit included checklists for physical environment and signage properties. This study matched the current physical environment properties of DHA's PHC Health Centers against WHO's recommendations. This is a cross sectional descriptive study that included visits to all 12 Primary Health Care Centers in Dubai city during August-September 2016 with the objective to assess the degree of fulfillment of current properties of Health Centers building to the recommendations of WHO as listed in "Age-friendly Primary Health Care Centres Toolkit" [1]. The study found that $81.86 \%$ of physical environment properties are matching the recommendation of $\mathrm{WHO}$, while signage matching was $44.6 \%$. The study concluded that most PHC properties have a physical design that met WHO's recommendations. The two major deviations were accessibility by public transportations and presence of grab bars. Factors that had a significant impact on design were compliance with multiple international and local standards, the availability of private cars, and the availability of wheel chairs. Signage in DHA's health centers followed a central plan that differed from WHO's recommendations.
\end{abstract}

\section{Keywords}

World Health Organization (WHO), Primary Health Care (PHC), Elderly Care Unit, Dubai Health Authority (DHA) 


\section{Introduction}

Elderly population in Dubai has almost doubled over the last decade from 10,797 (1.25\% of total Dubai population) in 2005, to an estimated 59,977 (2.45\% of total Dubai population) in 2015 [2]. Primary Health Care (PHC) is the front line of health care system of Dubai, putting it at the optimal position to serve the needs of this population. A total of 9,965,632 outpatients visits were recorded during the year of 2015 in Dubai, DHA received 22.2\% of them, and half of them were in the primary health care centers, while the other half were in hospitals or specialized centers [3].

According to a previous study conducted in 2015 on sources of care provided for elderly patients population in Dubai [4], primary health care centers were the primary source of health care for elderly (99\% of them), followed by DHA hospitals (60.9\%), then by Private hospitals (16.7\%), treatment abroad (10.2\%) and Ministry of Health facilities (2.3\%) [4].

Besides being the major source of healthcare for its elderly attendees, $27.5 \%$ of these elderly were partially or completely dependent in 3 functions of Activities of Daily Living (ADL) [4]. Thus, conformation of these HCs to accommodate the functional disabilities becomes very important. The Department of Ageing and Life Course (ALC) of WHO, has developed a toolkit to assist countries to deal with the peculiarities of elderly people in the setting of PHC [1]. This toolkit is also used to assess conformation of current PHC design to the needs of elderly in other countries [5] [6].

Elderly seeking PHC in Dubai can visit clinics as adults, or they can be referred to geriatric medicine services. These geriatric medicine services are provided by elderly care unit in primary health care centers, and include specialized geriatric medical services at homes, acute hospital care and outpatient clinics (three general geriatric medicine clinics, two osteoporosis clinics, one memory clinic and one falls clinic) distributed geographically in $6 \mathrm{HCs}$ to cover all catchment areas in Dubai.

Some of the peculiar factors in the experience of the elderly with health centers visits are the pivotal role of escort and private cars, and pursuing multiple international standards for care in the health centers.

Private cars being the prime means of transport in Dubai, as private light vehicles are widely prevalent; with a ratio of one private light vehicle for every two residents [7].

Despite the ongoing graying of population in the Gulf States and the advancing health system, published data on primary health care services for elderly in this region is scarce, particularly if compared to amount of available articles on other population groups. One study, published in 2013, with a similar scope, was conducted in Riyadh area, in Saudi Arabia [5], and it can be used as a benchmark for comparison, due to the social, cultural and economic comparable environment.

This article describes the degree of buildings designs conformation to seniors' needs (Elderly population) in primary health care centers belonging to Dubai 
Health Authority in Dubai, UAE.

\section{Objective}

To assess the degree of buildings designs conformation to the recommendations of WHO as listed in "Age-Friendly Primary Health Care Centers Toolkit".

\section{Methods}

This is a cross sectional, descriptive and quantitative study based on observing, assessing and analyzing data collected from 12 primary health care centers of DHA in Dubai at a specific point in time from September $16^{\text {th }} 2016$ until October $27^{\text {th }} 2017$ (six weeks). The properties of primary health care centers were checked against recommendations for building design and signage checklists as recommended by WHO in "Age-Friendly Primary Health Care Centers Toolkit" [1].

Two experts, one healthcare provider and one engineer trained on the checklists visited the twelve health centers during allocated period of time to check if design of the buildings and signage are convenient and in conformity to the elderly patients. Two checklists were used in the visits, one for physical building design and the other for signage. The building and design checklist has 44 properties items, and signage checklist has 20 properties items.

All items on the checklists were addressed in all health centers, except physical design items in buildings that have more than a ground floor, as there were only four centers with services present in more than one floor.

The results were presented in tables. Every item on the tables represents a single building and design or signage property on the checklist. The tables show the percentage of centers properties matching the recommendation of the WHO. The items (properties) on the checklist were re-organized and grouped for ease of explanation.

Data was recorded and analyzed manually using Microsoft excel 2013, and Microsoft Windows 7 platform.

\section{Results}

PHC Health centers in Dubai have three patterns of outlays designs. First pattern is a new two-level health center, stellate in floor plan layout, provided with grab bars on walls, three health centers have this pattern.

Second pattern has an older single-floor circular plan layout, without grab bars, five health centers have this pattern.

In the third pattern, the remaining health centers did not follow either outlays. Four health centers have this pattern with clinical services distributed on two levels of the building in three of them.

Table 1 and Figure 1 show spatial patterns of health centers in Dubai.

Table 2 shows that most of primary health care centers building and design properties matched the recommendations stated in WHO's Age-Friendly PHC 
toolkit (pooled average $81.86 \%$ ) with about $43 \%$ of the building and design properties existed as recommended in all centers $(19 / 44,43 \%)$. The frequency of availability of examined properties is markedly skewed towards actual existence (median percentage 92\%). Four health centers had two floors, while the rest had only a ground floor. The design elements of the entrances in the health centers are generally matching recommendations of WHO for age-friendly PHC design.

On the other hand, Table 3 shows much less fulfillments of the recommendations of WHO's Age-Friendly PHC signage properties toolkit. (Pooled average $44.6 \%$ ) with about $35 \%$ only of the signage properties existed as recommended in all centers $(7 / 20,35 \%)$ and $35 \%$ as well were completely not existing as recommended in all health centers $(7 / 20,35 \%)$.

\section{Discussion}

The PHC of DHA is JCI accredited [8], in addition, recently received six ISO certificates [9]. Therefore, DHA's standards in health centers design, administration and clinical services are high.

Most of the properties of the building and design met the recommendations of WHO's toolkit $(81.6 \%)$. The primary health care centers were originally built taking in consideration the best practices. This is due to the fact that the design and utilities in the health centers have been continuously revised and improved with each accreditation process. While most of the physical building and design specifications met the recommendations in the WHO toolkit, the signage specifications did not $(44.6 \%)$, due to a common uniform design of signs, which did

Table 1. Spatial patterns of primary health care centers in Dubai.

\begin{tabular}{|c|c|c|c|c|}
\hline Services & $\begin{array}{c}\text { Stellate floor } \\
\text { layout }\end{array}$ & $\begin{array}{l}\text { Circular floor } \\
\text { layout }\end{array}$ & $\begin{array}{l}\text { Neither } \\
\text { layouts }\end{array}$ & Total \\
\hline Services on ground floor only & 0 & 5 & 3 & 8 \\
\hline Services on two floors & 3 & 0 & 1 & 4 \\
\hline Total & 3 & 5 & 4 & 12 \\
\hline
\end{tabular}

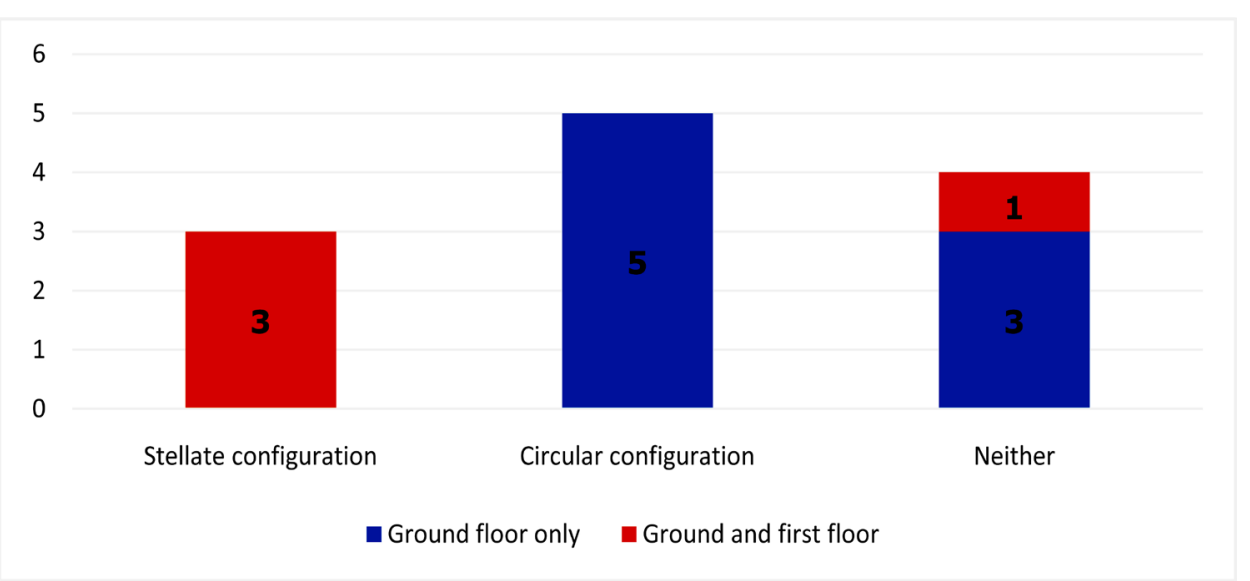

Figure 1. Design configurations of health centers in Dubai. 
Table 2. Dubai primary health care centers building and design checklist results.

\begin{tabular}{|c|c|c|c|}
\hline \multirow{2}{*}{$\#$} & \multirow{2}{*}{ Properties items } & \multicolumn{2}{|c|}{ HC matching WHO recommendations for seniors needs } \\
\hline & & Number & $\%$ \\
\hline & \multicolumn{3}{|c|}{ Access to the health center $(\mathrm{N}=12)$} \\
\hline 1. & $\mathrm{HC}$ is served by public transportation & 8 & 67 \\
\hline 2. & Closest station $<50$ meters & 2 & 17 \\
\hline 3. & Sufficient size of parking lot & 7 & 58 \\
\hline \multirow[t]{2}{*}{4.} & Dedicated parking for disabled/older near entrance & 11 & 92 \\
\hline & \multicolumn{3}{|c|}{ Walking assistance features-Wheelchairs and grab bars $(\mathrm{N}=12)$} \\
\hline 5. & Before the entrance, are there steps? & 7 & 58 \\
\hline 6. & Do steps have railings? & 3 & 25 \\
\hline 7. & Is there a ramp? & 12 & 100 \\
\hline 8. & Does the ramp have railings? & 4 & 33 \\
\hline 9. & Does the ramp have a gentle slope? & 9 & 75 \\
\hline 10. & Entrance-Width $>90$ centimeters & 12 & 100 \\
\hline 11. & Entrance-Type of door; sliding? & 9 & 75 \\
\hline 12. & Entrance-Accessible to wheelchair & 12 & 100 \\
\hline 13. & Entrance-Landing area free & 12 & 100 \\
\hline 14. & Doors width $>90$ centimeters & 12 & 100 \\
\hline 15. & Minimum unobstructed width for wheelchair & 10 & 83 \\
\hline 16. & Pathway is obstruction free & 11 & 92 \\
\hline 17. & Corridors have minimum unobstructed width for wheelchair. & 12 & 100 \\
\hline 18. & corridor/pathway obstruction-free & 11 & 92 \\
\hline 19. & Spare wheelchairs & 12 & 100 \\
\hline 20. & Grab bars & 6 & 50 \\
\hline 21. & Handrails/grab bars in corridors? Inner space and amenities $(\mathrm{N}=12)$ & 6 & 50 \\
\hline 22. & Rooms and corridors well-lit and ventilated & 12 & 100 \\
\hline 23. & Sitting arrangement is comfortable & 12 & 100 \\
\hline 24. & Furniture and fittings reduce falls & 11 & 92 \\
\hline 25. & Floor is non-slippery and well maintained & 11 & 92 \\
\hline 26. & Public telephone near the waiting area & 12 & 100 \\
\hline 27. & Eating outlet within the building & 12 & 100 \\
\hline 28. & Eating outlet is accessible & 12 & 100 \\
\hline 29. & Toilets_Near waiting hall & 11 & 92 \\
\hline 30. & Toilets-Entrance accessible to wheelchair & 8 & 67 \\
\hline 31. & Toilets_Accessible shower & 12 & 100 \\
\hline 32. & Toilets_Grab bars & 9 & 75 \\
\hline 33. & Toilets_Fittings are usable & 8 & 67 \\
\hline
\end{tabular}




\section{Continued}

\begin{tabular}{|c|c|c|c|}
\hline & \multicolumn{3}{|c|}{ Health center layout $(\mathrm{N}=12)$} \\
\hline 34. & Rooms organized logically & 9 & 75 \\
\hline 35. & Reception counter near entrance and identifiable & 12 & 100 \\
\hline 36. & Emergency exists identifiable & 12 & 100 \\
\hline 37. & Supportive staff & 12 & 100 \\
\hline \multicolumn{4}{|c|}{ Health centers with more than one floor $(\mathrm{N}=4)$} \\
\hline 38. & Elevator-Accessible to every floor & 4 & 100 \\
\hline 39. & Elevator-Accessible path to the lift? & 4 & 100 \\
\hline 40. & Elevator-Door easy to identify? & 4 & 100 \\
\hline 41. & Stairs- are steps friendly to elderly people (uniform and identifiable) & 2 & 50 \\
\hline 42. & Stairs-Are there handrails or grab bars & 3 & 75 \\
\hline 43. & Stairs-Are the handrails continuous & 3 & 75 \\
\hline 44. & Stairs-Is the height of the rails $80-90 \mathrm{~cm}$ from floor? & 3 & 75 \\
\hline \multicolumn{3}{|c|}{ Pooled average of meeting recommended properties } & $81.86 \%$ \\
\hline \multicolumn{3}{|c|}{ Mode } & 100 \\
\hline \multicolumn{3}{|c|}{ Median } & 92 \\
\hline
\end{tabular}

Table 3. Dubai primary health care centers signage checklist results.

\begin{tabular}{|c|c|c|c|}
\hline \multirow{2}{*}{$\#$} & \multirow{2}{*}{ Properties items } & \multicolumn{2}{|c|}{ HC matching WHO recommendations for seniors needs } \\
\hline & & Number & $\%$ \\
\hline 1. & Characters and background are matte/non-glare finish & 12 & 100 \\
\hline 2. & Characters contrast with background & 12 & 100 \\
\hline 3. & Simple and understood able. Only key words & 12 & 100 \\
\hline 4. & $\begin{array}{l}\text { For manual boards, black felt signs on white/light yellow, on a } \\
\text { non-glossy background }\end{array}$ & 12 & 100 \\
\hline 5. & Welcoming tone & 12 & 100 \\
\hline 6. & Identifying signs inside building for accessible areas & 12 & 100 \\
\hline 7. & Clearly marked emergency exits & 12 & 100 \\
\hline 8. & Staff initiates introduction to sensory-deprived patients & 10 & 83 \\
\hline 9. & Directional signs at points of change of direction & 6 & 50 \\
\hline 10. & Identifying signs outside building for accessible areas & 2 & 17 \\
\hline 11. & Guiding signs outside building on routs & 2 & 17 \\
\hline 12. & Understandable room numbering & 2 & 17 \\
\hline 13. & Familiar pictures to community are used to increase effectiveness & 1 & 8 \\
\hline 14. & Increasing effectives and emphasize key points by color & 0 & 0 \\
\hline 15. & Non-glare glass billboard for directions & 0 & 0 \\
\hline 16. & Braille signage & 0 & 0 \\
\hline 17. & Placement of all signs at eye level & 0 & 0 \\
\hline 18. & Sings are viewable from intended distance & 0 & 0 \\
\hline 19. & Personnel are easily identifiable through badges & 0 & 0 \\
\hline 20. & Name board for staff on duty & 0 & 0 \\
\hline & Pooled average & & 44.6 \\
\hline & Mode & & 100 \\
\hline & Median & & 17 \\
\hline
\end{tabular}


not allow much flexibility to accommodate the variations in health centers spatial layouts.

Conforming physical design properties to the needs of seniors is affected by external factors as the simultaneous compliance to multiple accreditation requirements, the local building licensing code, and the needs of other community groups attending the same HC with the seniors. Health Regulation Department of DHA issued a guide [9], which specifies requirement for licensing an outpatient facility in Dubai, including many building design. In general, the requirements of these factors were aligned with WHO's recommendations, and contributed to the high degree of concordance between WHO's recommendations and health centers building properties.

Although public transportations are covering a wide geographic area, and are well equipped for use by seniors and disabled, $67 \%$ health centers are not easily accessible by public transportations. The reason could be the fact that private cars being the prime means of transport in Dubai, as private light vehicles are widely prevalent; there were 1,234,634 private light vehicle licenses [7] for an estimated 2,327,350 Dubai residents in 2014 [10], with a ratio of one private light vehicle for every two residents ( 0.53 car per capita). Therefore, the availability of private cars and lower cost of fuel may play a major role in reliance on private transports.

This dependence on private cars is also evident in a society with similar culture in city of Riyadh, Kingdom of Saudi Arabia; where private cars represented $93.4 \%$ of all types of vehicles, and $58 \%$ of families own two or more private cars [11]. This situation is matching that of Riyadh health centers, where none of them was served by public transportation.

Since almost all seniors attend health centers by private transportations, parking areas around health centers become more important to patients, especially disabled ones. As part of building code in DHA regulation guide, all health centers in Dubai have at least one parking lot for disabled, except in the oldest health centers, where parking lot for disabled was allocated for ambulance. The availability of parking lots for disabled is relatively higher in Dubai health centers (92\%) than in Riyadh health centers (33\%).

Only two health centers in Dubai had signs on main roads pointing to their location, because they are the only health centers that satisfied municipality regulations, which restrict road signs for health facilities that work 24 hours with a number of in-patients beds only.

Inside health centers, grab bars were not available in $50 \%$ of Health centers (esp. older ones). This is may be due to the wide use of wheel chairs for assisting mobility. The sufficient availability of wheel chairs and the adaptation of the building design (entrance ramps, door and corridor width...) to their use are licensing pre-requisites [12], but grab bars installation is not a pre-requisite for licensing by DHA guide. All these factors together may have contributed to the low adoption of grab bars in Dubai's health centers. In a culturally and econom- 
ically comparable primary health system, the situation is replicated in Riyadh health centers [5], where building design related to wheelchairs match the recommendations of WHO toolkit in all health centers (100\%), while grab bars in corridors are present only in two health centers (13\%).

Primary health care centers in Dubai have sliding main doors, except in three health centers, which may be difficult to use for patients coming on wheelchairs. This was solved in two of these three health centers by providing a side entrance with sliding doors, and all seniors who visit the HCs on wheelchair come with the driver or one of their family members who provide necessary support. Additionally health centers, staff are trained to be always available for help in reception, immediately next to main doors.

The amenities of most of the health centers met the recommendations of WHO's toolkit, with the exception of toilets compatibility with the wheelchair users. This problem was significantly present in some older generation health centers.

Where toilet's fittings were not usable, it was mostly due to the inappropriate space layout for wheelchair maneuvering. Riyadh health centers has similar problem with compatibility to wheelchairs. Yet, meeting WHO toolkit's recommendations was higher in Dubai in this group of items relevant to amenities. The most distinctive difference between the health centers in Dubai and Riyadh appears in the presence of eating outlet and public phone in all Dubai centers, but in none in Riyadh.

There is a great difference when it comes to meeting the recommendations of WHO's toolkit for signage; it's relatively much lower conformity rate than physical building properties, with most of signage items were either present in all HCs or absent in all. This is because signage policy is central, and all signs themes are uniform across all DHA's health centers. They are black and white, with three letter sizes, and void of pictures with one health center exception.

Most of the mismatching properties are related to misplacement (at eye level, at a viewable distance, at points of change of directions) or non-placement (on main roads, on personnel, Braille signs).

The deviations from recommendations in the quality of already present signage design are in implementation of colors and familiar pictures, which is a distinctive feature between signs in DHA health centers and Riyadh health centers ( $0 \%$ vs $73.3 \%$ respectively for implementing both colors and pictures). It's worth mentioning that health centers in Dubai and Riyadh neither have Braille signs nor have listing staff on duty and their duty on name board. All Dubai DHA personnel carry ID badges with pictures all the time, but the letter size is small enough to be read by visitors.

\section{Conclusion}

Most properties of physical design of primary health care centers in Dubai meet recommendation stated in the WHO age-friendly primary health care centers 
toolkit. The two major deviations are accessibility by public transportations and presence of grab bars. Variables that had a significant impact on design are compliance with multiple international accreditation standards, the availability of private cars, and the availability of wheel chairs. Signage in DHA health centers follows a central plan that differs from WHO's recommendations, and personnel are not adequately identified.

\section{Conflict of Interest}

The authors declare that they do not have any conflict of interest.

\section{References}

[1] World Health Organization (2008) Age-Friendly PHC Centres Toolkit. http://www.who.int/ageing/publications/upcoming_publications/en/

[2] Dubai Statistics Center (2015) Chapter 1: Population and Vital Statistics, Table (01-04). https://www.dsc.gov.ae/Publication/\%D8\%A7\%D9\%84\%D8\%A8\%D8\%A7\%D8\%A 8\%20\%D8\%A7\%D9\%84\%D8\%A3\%D9\%88\%D9\%84-\%20\%D8\%A7\%D9\%84\%D8\% B3\%D9\%83\%D8\%A7\%D9\%86.pdf

[3] Dubai Health Authority (2015) Dubai Annual Health Statistical Report 2015. https://www.dha.gov.ae/DHAOpenDataAr/Annual\%20Statistical\%20Books/DHAD oc768681140-28-07-2016.pdf

[4] Al Yousef, N.J., Hussein, H., Al Faisal, W., Makhlouf, M.M. and Wasfy, A. (2015) Prevalence of Functional Disabilities and Sources of Care Provided for Elderly Patients Population in Dubai, UAE. Advances in Applied Psychology, 1, 6-9. http://webcache.googleusercontent.com/search?q=cache:xSv8H9jR660J:files.aiscien ce.org/journal/article/pdf/70340008.pdf $+\& \mathrm{~cd}=1 \& \mathrm{hl}=\mathrm{en} \& \mathrm{ct}=\mathrm{clnk} \& \mathrm{gl}=\mathrm{ae}$

[5] Alhamdan, A.A., Alshammari, S.A., Al-Amoud, M.M., et al. (2015) Evaluation of Health Care Services Provided for Older Adults in Primary Health Care Centers and Its Internal Environment. A Step towards Age-Friendly Health Centers. Saudi Medical Journal, 36, 1091-1096.

https://www.smj.org.sa/index.php/smj/article/view/smj.2015.9.11789/7581 https://doi.org/10.15537/smj.2015.9.11789

[6] Woo, J., Mak, B. and Yeung, F. (2013) Age-Friendly Primary Health Care: An Assessment of Current Service Provision for Older Adults in Hong Kong. Health Services Insights, 6, 69-77. https://www.ncbi.nlm.nih.gov/pmc/articles/PMC4089682/ https://doi.org/10.4137/HSI.S12434

[7] Department of Statistics (2014) Dubai Road and Transportation Authority (RTA) - The Annual Statistics Report 2014.

https://www.rta.ae/wps/wcm/connect/rta/ea35d56c-4a63-4183-836b-0cfec716970c/An nual+Report+New+design-V6-Lowres.pdf?MOD=AJPERES\&CACHEID $=e a 35 \mathrm{~d} 56 \mathrm{c}$ $-4 \mathrm{a} 63-4183-836 \mathrm{~b}-0 \mathrm{cfec} 716970 \mathrm{c}$

[8] Joint Commission International (2017) JCI-Accredited Organizations. United Arab Emirates-Primary Health Care.

http://www.jointcommissioninternational.org/about-jci/jci-accredited-organization s/?c=United\%20Arab\%20Emirates\&a=Primary\%20Care\%20Program

[9] Dubai Health Authority (2016) Eleven Primary Health-Care Centers Run by DHA Receive Six ISO Certification.

https://www.dha.gov.ae/en/DHANews/Pages/DHANews953853650-09-10-2016.aspx 
[10] Dubai Statistical Center (2014) Population by Sex and Age Groups-Emirate of Dubai. https://www.dsc.gov.ae/Report/DSC_SYB_2014_01\%20_\%2003.pdf

[11] High Commission for the Development of Arriyadh (2016) Riyadh Population Studies, 1437 Hijri.

http://www.ada.gov.sa/idc/groups/public/documents/AR_ADA_Researches/007523. pdf

[12] Health Regulation Department (2012) Outpatient Care Facilities Regulation. Ref. No. HRD/HRS/FRU007 ed. Dubai Health Authority, Dubai, United Arab Emirates: Health Regulation Department-Dubai Health Authority.

https://www.dha.gov.ae/Documents/Regulations/Guidelines/Health\%20Facility\%20 Guidelines\%20_Planning\%20Design\%20Construction\%20and\%20Commissioning.pdf 